Check for updates

Cite this: RSC Adv., 2017, 7, 36765

Received 8th July 2017

Accepted 19th July 2017

DOI: $10.1039 / c 7 r a 07515 d$

rsc.li/rsc-advances

\section{Self-assembled coronene nanofiber arrays: toward integrated organic bioelectronics for efficient isolation, detection, and recovery of cancer cells $\uparrow$}

\begin{abstract}
Po-Jung Chen, Rou-Zhen Liu and Yu-Sheng Hsiao*
The biological immobilization of antibodies onto geometrically controlled conducting/semiconducting nanostructures is a promising approach for directing efficient cell-substrate interactions at bioelectronic interfaces (BEIs), thereby facilitating the melding of biological systems with electronics. In this study, we employed a novel thin-film growth technology to fabricate three-dimensional (3D) organic smallmolecule semiconductor-based nanofiber (NF) arrays on transparent conducting electrodes, and examined their BEI integration for the isolation, detection, and recovery of circulating tumor cells (CTCs). During normal thermal evaporation, out-of-plane nanostructures of coronene (CR), a polycyclic aromatic small molecule, readily formed through template-assisted self-assembly. We exploited the synergistic effects of controllable CR-based NF structures and anti-epithelial cellular adhesion molecule (anti-EpCAM) coatings as nanovelcro cell-affinity assays to enhance the capture efficiency of targeted CTCs, while behaving as anti-adhesive surfaces for non-targeted cells. Because of the high integration capability and high optical transparency of CR-based NFs, optimizing the binding conditions of the antiEpCAM coatings allowed us to develop a liquid biopsy chip for the selective capture of CTCs and for the rapid/direct quantification (using a normal inverted optical microscope) of the number of captured CTCS; in addition, we designed this system such that it would allow electrically driven cell-release (using an electrochemical potentiostat). The desorption phenomena of PLL-g-PEG-biotin upon applying 20 cycles of cyclic voltammetry (voltage swept from 0 to $+1.0 \mathrm{~V}$ ) in PBS buffer triggered the electrical release of the captured CTCs from the CR-based NFs; integration of the CR-based NF substrate with an overlaid microfluidic PDMS chaotic mixer led to highly efficient cell-capture yields (>84\%) at various spiked densities of MCF7 cells in a THP-1 cell solution $\left(10^{6}\right.$ cells per $\left.\mathrm{mL}\right)$; over $90 \%$ of the resulting cells were viable. These 3D CR-based BEl devices suggest that new opportunities abound in the design of novel organic electronics for advanced biomedical applications.
\end{abstract}

\section{Introduction}

Films of strongly $\pi$-stacked small-molecule semiconductors have garnered great attention in the production of organic electronic devices; such materials display many properties that differ from those of their bulk counterparts. ${ }^{1-3}$ Organic molecules have several features that make them attractive alternatives to inorganic materials for use in electronics, including low cost, light weight, amenability to large-scale and low-temperature processing, and mechanical flexibility. ${ }^{4-6}$ For example, organic crystals composed of semiconducting small molecules can display enhanced electrical and optical performance because of their low defect densities (resulting from self-assembly and/or

Department of Materials Engineering, Ming Chi University of Technology, 84 Gunjuan Road, Taishan, New Taipei City 243, Taiwan.E-mail:yshsiao@mail.mcut.edu.tw; Fax: +886-2908-4091

$\dagger$ Electronic supplementary information (ESI) available. See DOI: 10.1039/c7ra07515d crystallinity), their quantum size effects, and the simplicity of their doping at the material level. ${ }^{7,8}$ Through fine control over the surface energy and temperature of the substrates during the normal thermal evaporation process, the self-assembly of small molecules in particular has been studied extensively, allowing the construction of a variety of nanostructures for use in organic electronics. For example, the in-plane morphologies (planar structures) of small-molecule thin films have been exploited widely in organic light emitting diodes (OLEDs) and organic fieldeffect transistors (OFETs), ${ }^{9}$ while out-of-plane three-dimensional (3D) morphologies [nanofiber (NF) arrays] of active layers have been generally developed for organic photovoltaics (OPVs) and organic field emitters. ${ }^{10-14}$ Although the use of organic small molecule (OSM) semiconductors as device active layers has been examined for the development of organic bioelectronics, ${ }^{15-17}$ practical examples of their applications in cell-based bioelectronics have been very rare, due to the lack of reliable techniques for controlling the 3D morphologies of OSM thin films and for regulating cell-matrix interactions at the device level. 
Circulating tumor cells (CTCs) are shed from solid primary tumors and arrive in the peripheral bloodstream with the capability to form distant metastases; they are, therefore, potentially accessible sources for cancer diagnosis and the monitoring of disease progression. Cell phenotyping and molecular characterization of CTCs in blood samples (liquid biopsies) can provide sufficient information for monitoring the full course of the tumor-specific changes, and for gauging the efficacy of the response of patients to treatment. ${ }^{18}$ Although analytical concepts using liquid biopsies may be adapted to a variety of procedures for cancer diagnosis, the identification and isolation of CTCs in blood samples are both technically challenging, due to the extremely low concentrations of CTCs, relative to hematologic cells, in the blood (only a few to a few hundred CTCs for every billion blood cells). In addition to approaches exploiting individual physical (e.g., size, density, electric charge, deformability) and biological (e.g., surface conjugation with specific biomolecules) properties, ${ }^{19-21}$ recent research into nanostructures has revealed that the synergistic effects of surface modification and immunoaffinity can lead to the recognition and capture of CTCs with high efficiency and specificity. For example, vertical (out-of-plane) nanostructures of silicon nanopillars ${ }^{22-29}$ and nanostructured arrays of the conducting polymer poly(3,4-ethylenedioxythiophene) (PEDOT),,$^{30-32}$ and horizontal (in-plane) nanostructures of poly(lactic-co-glycolic acid) (PLGA), ${ }^{33} \mathrm{TiO}_{2},{ }^{34}$ nylon-6 NFs, ${ }^{35}$ and other nanostructures, ${ }^{36-38}$ can all serve in nanovelcro cell-affinity assays for the highly efficient capture of cancer cells. The further integration of organic 3D bioelectronic interfaces (BEIs), including conducting polymers, carbon materials, and OSM semiconductors on chips, should enhance the applications of bioelectronics in cancer research.

In a previous study, we found that large-scale reduced graphene oxide (rGO) coatings could transform metal-free phthalocyanine $\left(\mathrm{H}_{2} \mathrm{Pc}\right)$ films into vertical standing nanostructures on transparent indium tin oxide (ITO) electrodes during the normal thermal evaporation process. ${ }^{\mathbf{1 4}}$ Although we used the preliminary results to develop OSM-based organic field emitters, we were aware that this 3D thin-film growth technology would have high integration capability and flexibility in bioelectronics and advanced biomedical applications, especially for CTC isolation and detection through the synergistic effects of surface modification and immunoaffinity. To the best of our knowledge, OSM-based NanoVelcro chips have yet to be used widely in CTC liquid biopsy assays. Accordingly, in this study we developed coronene (CR)-based NF arrays as organic 3D BEIs through optimization of the electrode identity, deposition thickness, and biofunctionalization process. Furthermore, we integrated these CR-based 3D BEIs into bioelectronics to study their ability to capture and recover CTCs (Fig. 1).

\section{Experimental section}

\section{Materials and reagents}

Fabrication of CR-based NF arrays and microfluidic device assembly. Graphene oxide (GO) aqueous dispersion, prepared using a modified Hummers method, was purchased from
Graphenea at a concentration of $4 \mathrm{mg} \mathrm{mL}^{-1}$. A resulting GO aqueous solution $(0.1 \mathrm{wt} \%)$ was prepared for spin-casting, using a mixture of methanol and water ( $4: 1$, vol/vol; $3 \mathrm{~mL})$ to dilute the pristine GO solution ( $1 \mathrm{~mL}$ ). A GO film was spin-cast upon a cleaned ITO substrate. The GO film was chemically reduced in hydrazine vapor at $110{ }^{\circ} \mathrm{C}$ for $6 \mathrm{~h}$ to obtain the large-scale reduced GO layers on ITO glass. All devices were fabricated on patterned ITO glasses $\left(<7 \Omega \mathrm{sq}^{-1}\right)$ that had been cleaned sequentially with detergent, DI water, acetone, and isopropyl alcohol. After the routine cleaning, the ITO substrates were treated with air-plasma for $15 \mathrm{~min}$ at $18 \mathrm{~W}$ in low-pressure $(0.2$ mbar) residual air (Harrick Plasma Cleaner, PDC-32G, Harrick Scientific, NY). CR thin films were subsequently deposited onto three different kinds of transparent conducting electrode (ITO, GO-coated ITO, rGO-coated ITO) using a thermal evaporator operated at a base pressure of $5 \times 10^{-6}$ torr. A commercially available CR powder (purity: 97\%; Aldrich) was used as received. The sublimation of the CR powder was performed at a crucible temperature of $55{ }^{\circ} \mathrm{C}$. For all substrates, the corresponding deposition rate, controlled by a quartz crystal microbalance (QCM), was $1 \AA \mathrm{s}^{-1}$. The deposition times for the ITO, GO/ITO, and rGO/ITO electrodes were approximately 16.7 and $83.3 \mathrm{~min}$; the resulting $\mathrm{CR}$ thicknesses, monitored by QCM, were approximately 100 and $500 \mathrm{~nm}$, respectively. The microfluidic device configuration of the CR thin film-coated rGO/ITO electrode was assembled with a chaotic mixer to obtain a PDMS microchannel with 11 channels (each continuous PDMS channel in this device was $70 \mu \mathrm{m}$ high, $1 \mathrm{~mm}$ wide, and approximately $22 \mathrm{~cm}$ long).

Characterization. Raman spectra of the GO and rGO materials were recorded using a micro-Raman spectrometer (alpha 300, WITec Instruments, Germany; resolution: $1 \mathrm{~cm}^{-1}$; laser excitation: $514.5 \mathrm{~nm}$ ). Scanning electron microscopy (SEM, FEI Nova NanoSEM 200; accelerating voltage: $10 \mathrm{keV}$ ) was used to record top and cross-sectional views of the morphologies of the CR-based NF arrays and CTCs on chips. Prior to SEM examination, the biological and CR-based samples were dehydrated in ascending grades of $\mathrm{EtOH}(25,50,75$, and 100\%; each dehydration time: $20 \mathrm{~min}$ ), subjected to critical point drying with liquid $\mathrm{CO}_{2}$, and sputter-coated with gold $(<3 \mathrm{~nm})$. The crystalline structures of the CR NF arrays and CR powders were characterized using grazing-incidence X-ray diffraction (GIXRD; Philips PANalytical X'Pert PRO MRD apparatus; $\mathrm{Cu} \mathrm{K} \alpha$ radiation); the incident X-ray beam angle was fixed above the critical angle at $5^{\circ}$. Transmission electron microscopy (TEM) and highresolution TEM (HRTEM) images and corresponding selectedarea electron diffraction (SAED) patterns of the CR NFs were obtained using a JEOL-2100F transmission electron microscope operated at an accelerating voltage of $200 \mathrm{kV}$. Contact angles (CAs) were determined on each substrate using the geometric mean approximation with DI water. Chemical configurations were determined using X-ray photoelectron spectroscopy [XPS; PHI5000 VersaProbe apparatus and a monochromatic $\mathrm{Al} \mathrm{K} \alpha \mathrm{X}$ ray source (1486.6 eV) for sample excitation]. Cyclic voltammetry (CV) and electrochemical impedance spectroscopy (EIS) were performed using a potentiostat/galvanostat (PGSTAT204, Autolab, Eco Chemie, Netherlands) with a frequency response 


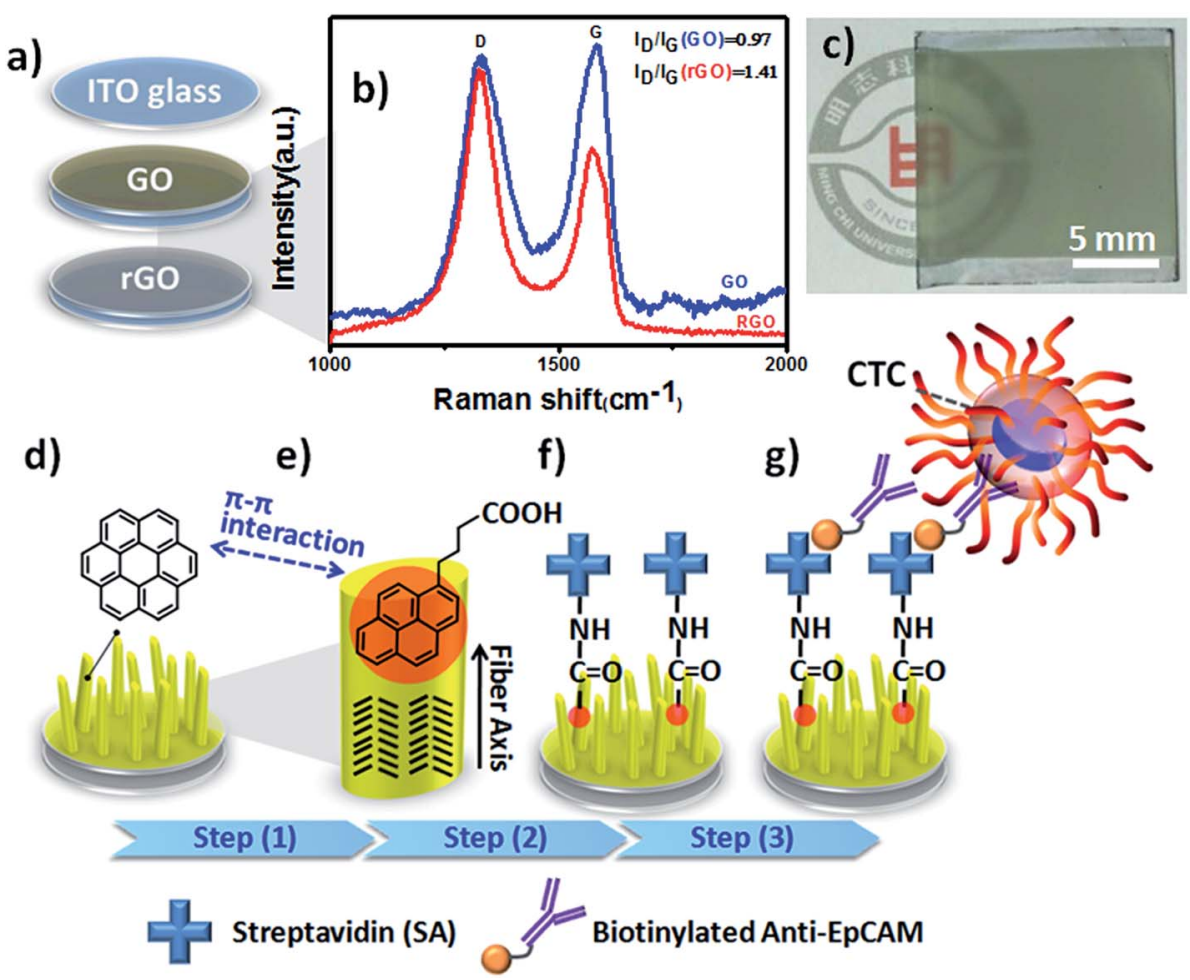

Fig. 1 (a) Schematic representation of various coatings of ITO substrates. (b) Raman spectra of GO and rGO coatings recorded at an excitation laser wavelength of $514.5 \mathrm{~nm}$. (c) Photograph of a CR-based NF array film deposited on an rGO-coated ITO electrode (NF3-500). (d-g) Schematic representation of the surface modifications of a 3D CR-based NF device and its coating architecture for efficient capture of cancer cells. (d) Chemical structure of CR and CR-based NF arrays deposited through a TE process at a value of $T_{\text {sub }}$ of $25^{\circ} \mathrm{C}$. (e) PBA monolayers adsorbed on CR-based NF arrays through $\pi-\pi$ stacking. (f) Conjugation of SA to PBA-modified CR-based NF arrays through EDC/NHS activation. (g) Conjugation of biotinylated anti-EpCAM on the device and its application for the capture of CTCS on chips.

analysis (FRA) module in a three-electrode configuration in a glass cell. A Pt wire and a $\mathrm{Ag} / \mathrm{AgCl}$ electrode were used as the counter and reference electrodes, respectively. CV measurements were performed in $1 \times$ phosphate-buffered saline (PBS) over the potential range from 0 to $0.5 \mathrm{~V} v s$. $\mathrm{Ag} / \mathrm{AgCl}$ (scan rate: $100 \mathrm{mV} \mathrm{s}^{-1}$ ). EIS measurements were performed in $1 \times$ PBS buffer by applying an AC voltage (amplitude: $5 \mathrm{mV}$ ) to measure the ionic conductivity in the frequency range from $10^{-1}$ to $10^{4} \mathrm{~Hz}$ at the open circuit potential.

Surface modification of CR-based NF arrays. All CR-based NF arrays were functionalized through drop-coating with a modified solution of $2 \mathrm{mM}$ 1-pyrenebutyric acid (PBA, 97\%, SigmaAldrich) in 0.1 M sodium tetraborate (STB) buffer ( $\mathrm{pH} 9.2$ ) for $1 \mathrm{~h}$. Each sample was then washed with water to remove the non-adsorbed PBA and dried at room temperature. Except for those used in the study of electrically driven cell-release, all of the PBA-modified CR-based NF arrays were further modified with 1-(3-dimethylaminopropyl)-3-ethylcarbodiimide hydrochloride (EDC, $0.2 \mathrm{M}, \mathrm{TCI}$ ) and $\mathrm{N}$-hydroxysuccinimide (NHS, $0.05 \mathrm{M}$ ) in DI water. The PBA-modified CR films pre-activated with EDC and NHS were treated with streptavidin (SA, $10 \mu \mathrm{g}$ $\mathrm{mL}^{-1}$ ) for $90 \mathrm{~min}$. Biotinylated anti-human EPCAM/TROP1 antibody $\left(10 \mu \mathrm{g} \mathrm{mL}^{-1}\right.$ in $1 \times$ PBS containing $0.1 \%$ BSA and $0.09 \% \mathrm{NaN}_{3} ; 25 \mu \mathrm{L} ; \mathrm{R} \& \mathrm{D}$ Systems) was placed onto the substrate and incubated $(60 \mathrm{~min})$ at room temperature. For the cell- release experiments, a modified solution of PLL(20)- $g$ - $[3.5]-$ PEG(2)/PEG(3.4)-biotin (50\%) (PLL-g-PEG-biotin, SuSoS) was prepared at a concentration of $100 \mu \mathrm{g} \mathrm{mL}^{-1}$ in $10 \mathrm{mM} \mathrm{4-(2-}$ hydroxyethyl)-1-piperazineethanesulfonic acid (HEPES) buffer ( $\mathrm{pH}$ 7.4). The PBA-modified CR film was treated with PLL-gPEG-biotin for $1 \mathrm{~h}$ and then incubated with SA $\left(10 \mathrm{mg} \mathrm{mL}^{-1}\right.$ in $1 \times \mathrm{PBS}$ ) for $1 \mathrm{~h}$ at room temperature. Biotinylated anti-human EpCAM/TROP1 antibody $\left(10 \mathrm{mg} \mathrm{mL}^{-1}\right.$ in $1 \times$ PBS containing $0.1 \%$ BSA and $0.09 \% \mathrm{NaN}_{3} ; 25 \mathrm{~mL}$ ) was subsequently placed onto the device and then incubated $(60 \mathrm{~min})$ at room temperature. Finally, the CR-based NF arrays were washed several times with $1 \times$ PBS and then immersed in $1 \times$ PBS for $1 \mathrm{~h}$ prior to performing the cell experiments.

Cell studies. The breast cancer cell line (MCF7), cervical cancer cell line (HeLa), and monocytic leukemia cell line (THP1) were obtained from the Bioresource Collection and Research Center (BCRC, Taiwan). The lung adenocarcinoma cancer cell line (PC9) was kindly gifted by Prof. Sung-Liang Yu (Department of Clinical Laboratory Sciences and Medical Biotechnology, College of Medicine, National Taiwan University, Taiwan). The growth medium for the MCF7 and HeLa cells was Dulbecco's Modified Eagle's Medium (DMEM); the growth medium for the THP-1 and PC9 cells was RPMI 1640. These media contained $10 \%$ fetal bovine serum (FBS, Life Technologies) and penicillin and streptomycin $\left(100 \mathrm{mg} \mathrm{mL}^{-1}\right)$ and were incubated at $37^{\circ} \mathrm{C}$ in 
a humidified atmosphere of $5 \% \mathrm{CO}_{2}$. GlutaMAX-I, Vybrant ${ }^{\circledR}$ DiD cell labeling solution, DMEM, and RPMI 1640 medium were obtained from Invitrogen. FBS was obtained from Hyclone; DAPI and HEPES buffer were obtained from Life Technologies. For the Papanicolaou staining, Mayer's hematoxylin solution and Eosin Y solution were obtained from Sigma-Aldrich.

Cell capture/release experiments. After removing the $1 \times$ PBS from the 3D CR-based NF arrays, $200 \mu \mathrm{L}$ cell suspensions $\left(10^{5}\right.$ cells per $\mathrm{mL}$ ) were loaded onto chips having a diameter of 10 $\mathrm{mm}$ of PDMS reservoirs. After incubation for $60 \mathrm{~min}$ at $37{ }^{\circ} \mathrm{C}$ and $5 \% \mathrm{CO}_{2}$, the substrate was gently washed with $1 \times$ PBS (at least five times). Imaging and counting of cells was performed using a fluorescence microscope (CKX41, Olympus). Cell counts for dilution experiments and cell viabilities were determined using an automated cell counter (Luna ${ }^{\mathrm{TM}}$ automated cell counter, Logos Biosystems, Korea). Following the capture procedure described above, substrate-modified cancer cells were trypsinized and collected. Finally, the collected cells on each device were prepared in a $100 \mu \mathrm{L}$ cell suspension that was then carefully transferred to a counting slide for the Luna ${ }^{\mathrm{TM}}$ Automated Cell Counter apparatus. Cell viability was analyzed in triplicate. For the electrically triggered cell-releasing studies, the 3D CR-based NF devices were operated as a working electrode with a standard three-electrode setup, and cyclic potential electrical stimulation (ES) with four different kinds of voltage swept from -0.8 to $+0.5 \mathrm{~V}$, from 0 to $+0.5 \mathrm{~V}$, from 0 to $+0.8 \mathrm{~V}$, and from 0 to $+1.0 \mathrm{~V}$ at a scan rate of $100 \mathrm{mV} \mathrm{s}^{-1}$ for 20 cycles in $1 \times$ PBS. All experiments were repeated at least three times [all cell capture/release data are expressed as means \pm standard deviation (SD) for $n=900$ cells] and provided similar results.

\section{Results and discussion}

Based on observational evidence of the template-assisted self-assembly of OSM semiconductors, ${ }^{14}$ we have previously found that it is possible that rGO coatings and thermal evaporation can be used to control the vertical alignment of OSM (e.g., phthalocyanine) NFs on transparent ITO electrodes. With the goal of developing integrated transparent bioelectronic interfaces for the efficient isolation and detection of cancer cells, in this study we developed a simple approach-using three different transparent conducting electrodes (ITO, GO-coated ITO, rGO-coated ITO)-for controlling the growth of nanostructured CR-based thin films, which we studied as NF arrays for their corresponding cell-capture performance (Fig. 1). We were aware that the density of defects and degree of graphitization of GO and rGO coatings could result in different OSM NF structures after thermal evaporation deposition. Therefore, we recorded Raman spectra and calculated the ratio of the intensities of the $\mathrm{D}$ and $\mathrm{G}$ bands $\left(I_{\mathrm{D}} / I_{\mathrm{G}}\right)$. After applying the hydrazine vapor reduction method at $110{ }^{\circ} \mathrm{C}$ for $6 \mathrm{~h}$, the intensity ratio $\left(I_{\mathrm{D}} /\right.$ $I_{\mathrm{G}}$ ) changed from 0.97 for the GO-coated ITO to 1.41 for the rGOcoated ITO (Fig. 1b). This increase in the value of $I_{\mathrm{D}} / I_{\mathrm{G}}$ suggests that the oxygen functional groups of the GO sheets were removed and more graphene domains ( $\mathrm{sp}^{2}$-hybridized carbon) formed on the rGO sheets when using this chemical reduction method, while also revealing high transparency (Fig. 1c).
Fig. $1 \mathrm{~d}-\mathrm{g}$ present our proposed adaptable modification method for preparing anti-EpCAM coatings on CR-based NF array surfaces; it can be performed readily for further studies of the critical issues of CTC isolation and detection on chips. The device configuration was based on a three-step sequence of surface modification: (1) depositing PBA through $\pi-\pi$ interactions between pyrene and CR materials, (2) depositing SA through EDC/NHS activation of the terminal carboxylic acid groups of PBA, and (3) depositing biotinylated anti-EpCAM through SA-biotin binding. The resulting tunable CR-based NF structures presenting anti-EpCAM coatings served as nanovelcro cell-affinity assays for optimizing the rare-cell isolation.

We observed different aspect ratios (ARs) and fiber densities for the 3D CR-based NFs formed on the three different electrode surfaces (ITO, GO-coated ITO, rGO-coated ITO). As indicated in Fig. 2 and 3, we adopted two different deposition conditions to control the CR-based NF arrays, monitored using a QCM with a deposition rate of $1 \AA^{-1}$, to thicknesses of 100 and $500 \mathrm{~nm}$, respectively. Furthermore, we used the three different electrodes (ITO, GO/ITO, rGO/ITO) to fabricate CR-based NF thin films of various morphologies, due to their different surface energies, through thermal evaporation at a value of $T_{\text {sub }}$ of $25{ }^{\circ} \mathrm{C}$; the $3 \mathrm{D}$ CR-based $\mathrm{NF}$ arrays were formed on top of a smooth underlying layer and were associated nearly with a Stranski-Krastanov-type growth process (Fig. 2d-f and 3d-f). Notably, all-carbon-based (CR-based) NF arrays with different ARs and nanostructure densities were obtained by adjusting the deposition conditions; Fig. S1† presents the statistical analysis of the NF-related traits (e.g., fiber length, fiber diameter, aspect ratio, and number density) in this study. Samples of the $100 \mathrm{~nm}$ thick NF arrays deposited on the ITO, GO/ITO, and rGO/ITO electrodes are denoted NF1-100, NF2-100, and NF3-100, where the number 100 refers to the deposition thickness of the CRbased NF arrays (monitored using a QCM). Fig. 2 displays SEM images of the $100 \mathrm{~nm}$-thick of CR-based NF arrays and their size distributions. The average fiber lengths of NF1-100, NF2-100, and NF3-100 were 1221, 1002, and $917 \mathrm{~nm}$, respectively; the average fiber diameters were 88, 102, and $128 \mathrm{~nm}$, respectively. Interestingly, the number density of the NFs decreased in the order NF3-100 $>$ NF1-100 $\approx$ NF2-100 (Fig. S1d $\dagger$ ). Using the same sample nomenclature, the morphologies of the $500 \mathrm{~nm}$-thick NF arrays deposited on the ITO, GO/ITO, and rGO/ITO electrodes (NF1-500, NF2-500, and NF3-500, respectively) revealed (Fig. 3) a decrease in the number density of the NFs in the order NF3-500 $\approx$ NF2-500 $>$ NF1-500. Nevertheless, the NF densities obtained using the $500 \mathrm{~nm}$ thickness deposition conditions were generally higher than those of the $100 \mathrm{~nm}$-thickness conditions. The average fiber lengths of NF1-500, NF2-500, and NF3-500 were 1694, 1551, and $2007 \mathrm{~nm}$, respectively; the average fiber diameters of NF1-500, NF2-500, and NF3-500 were 183, 110, and $165 \mathrm{~nm}$, respectively.

Fig. 4a-d present GIXRD spectra of the CR powders and CR films formed on the various substrates through TE at a value of $T_{\text {sub }}$ of $25{ }^{\circ} \mathrm{C}$. The GIXRD patterns of the CR powders and nanorods were indexed well to the crystal structures of $\beta$-CR and $\gamma$-CR ${ }^{39}$ and indicated polycrystalline material. The peaks of $\gamma$-CR corresponding to the (10) $),(002),(10 \overline{3}),(20 \overline{2})$ and (112) planes, 

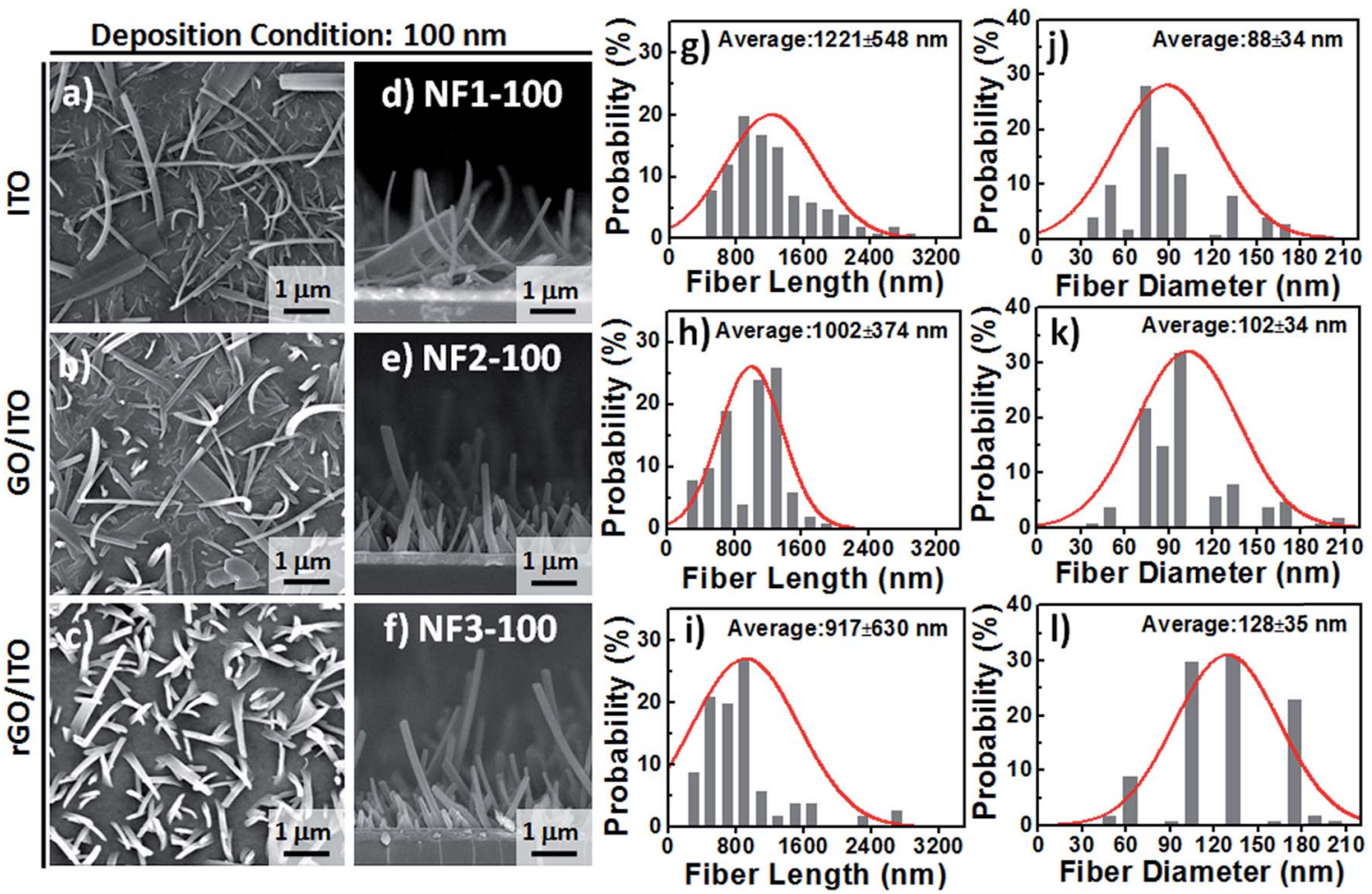

Fig. 2 Top-view and cross-sectional SEM images of CR-based thin films deposited on (a, d) ITO, (b, e) GO-coated ITO, and (c, f) rGO-coated ITO electrodes under the $100 \mathrm{~nm}$-thickness deposition conditions, denoted NF1-100, NF2-100, and NF3-100, respectively. (g-l) Histograms of the fiber lengths and fiber diameters of the CR NFs deposited on (a, d) ITO, (b, e) GO/ITO, and (c, f) rGO/ITO electrodes at a value of $T_{\text {sub }}$ of $25^{\circ} \mathrm{C}$.
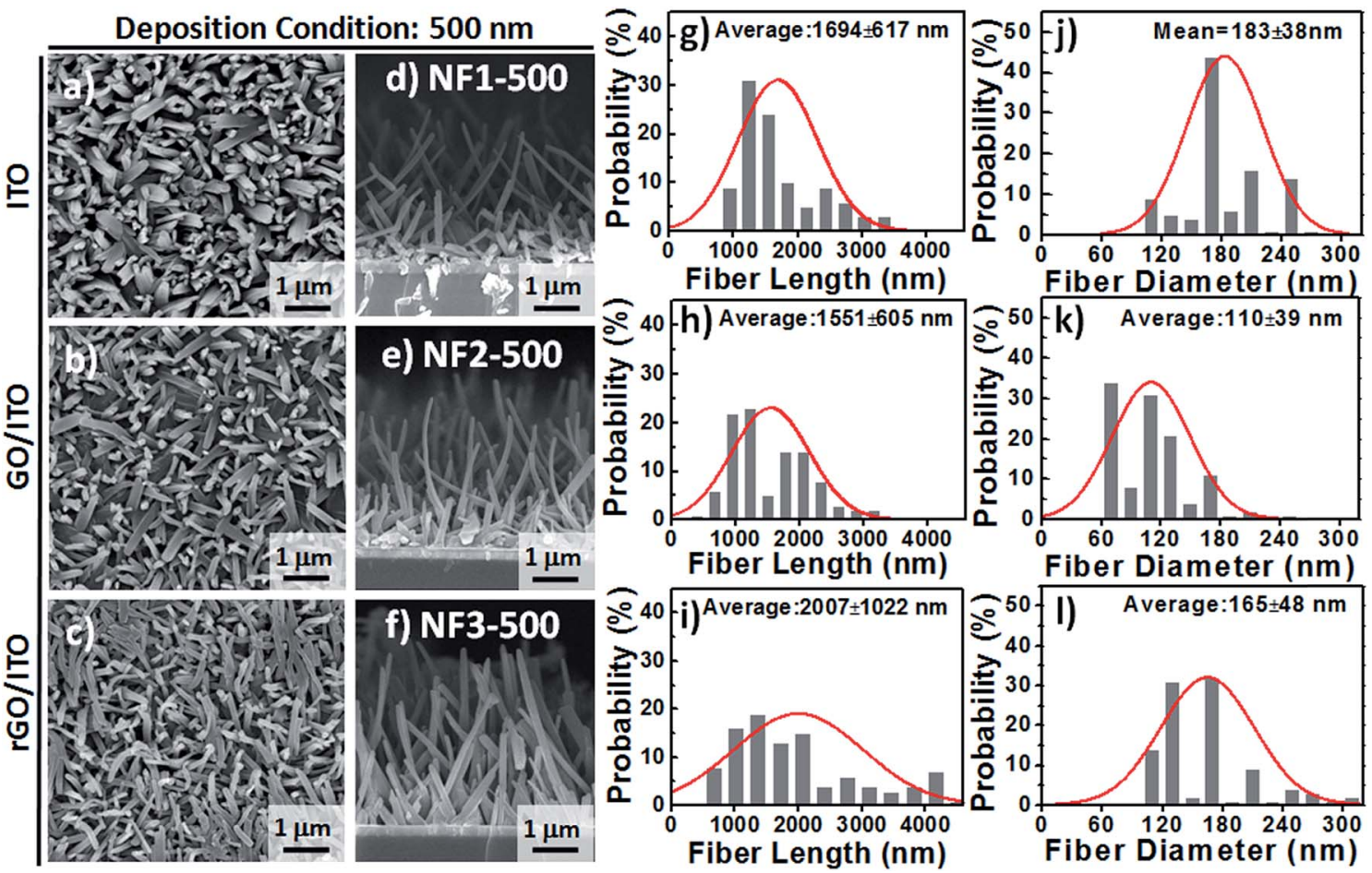

Fiber Diameter ( $\mathrm{nm}$ )
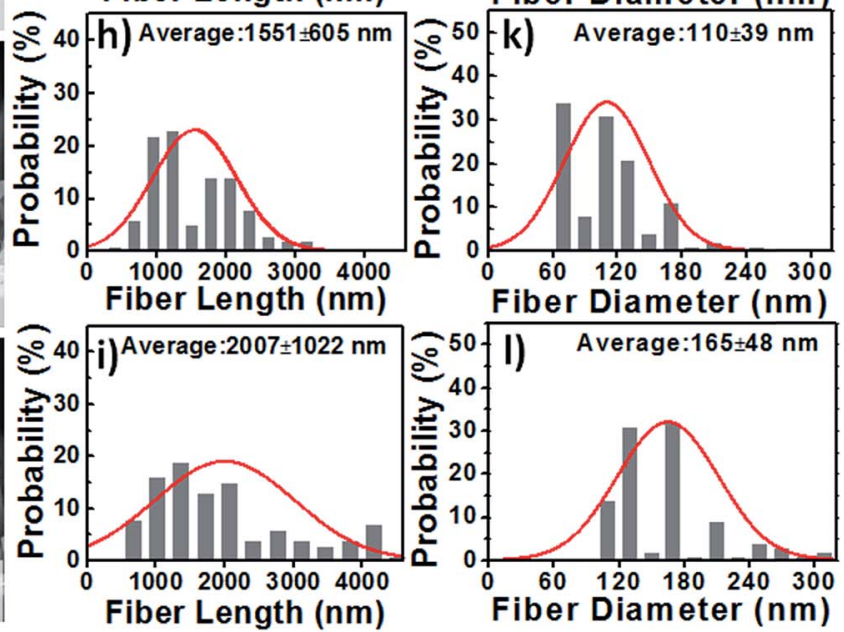

Fig. 3 Top-view and cross-sectional SEM images of CR-based thin films deposited on (a, d) ITO, (b, e) GO-coated ITO, and (c, f) rGO-coated ITO electrodes under the $500 \mathrm{~nm}$-thickness deposition conditions, denoted as NF1-500, NF2-500, and NF3-500, respectively. (g-l) Histograms of the fiber lengths and fiber diameters of the CR NFs deposited on (a, d) ITO, (b, e) GO/ITO, and (c, f) rGO/ITO electrodes at a value of $T_{\text {sub }}$ of $25^{\circ} \mathrm{C}$. 

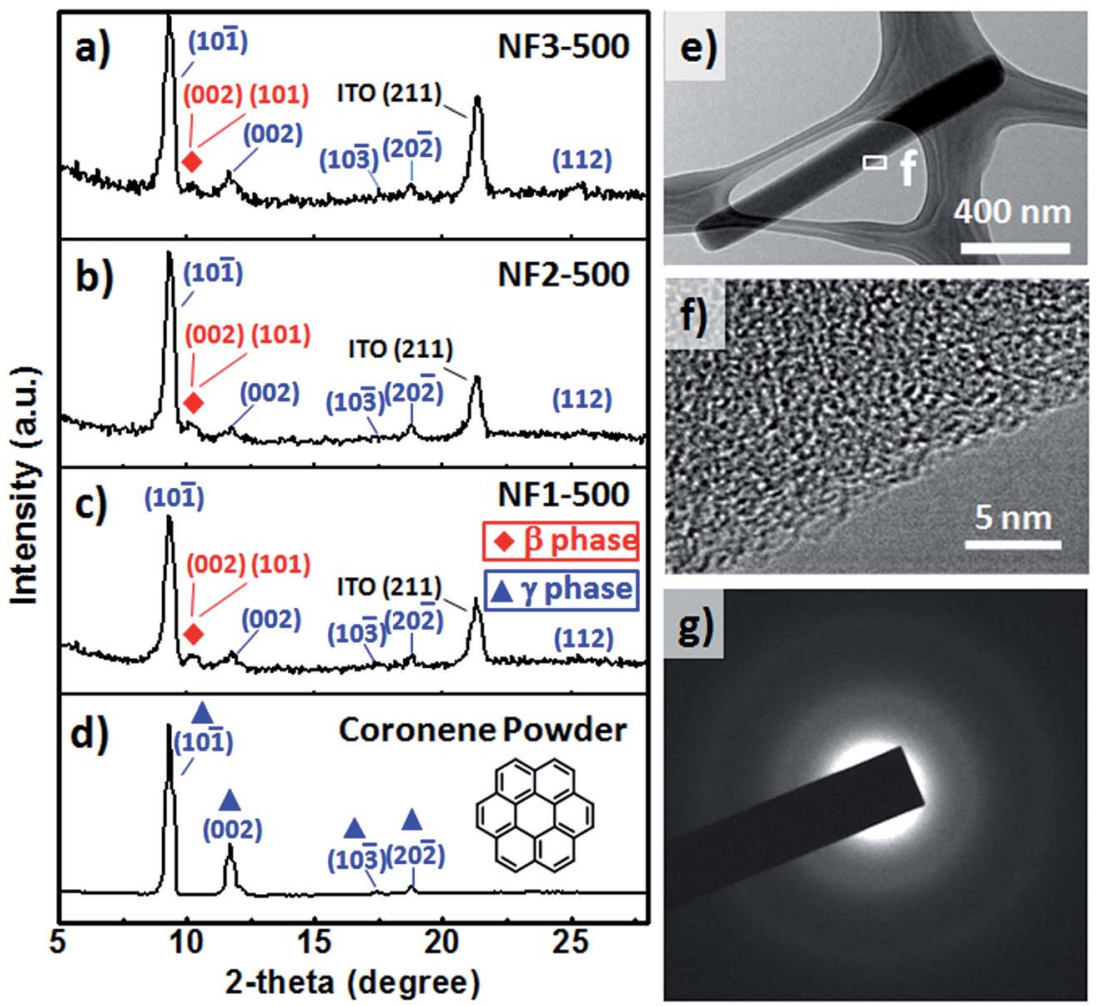

Fig. 4 (a-d) GIXRD spectra of powders and CR films formed on various electrodes under the 500 nm-thickness deposition conditions: (a) CRbased NF arrays on the rGO/ITO electrode (NF3-500); (b) CR-based NF arrays on the GO/ITO electrode (NF2-500); (c) CR-based NF arrays on the rGO/ITO electrode (NF3-500); (d) CR-based NF arrays on the ITO electrode (NF1-500); (d) CR powders. (e) TEM image of a single CR NF formed on the rGO/ITO electrode (NF3-100). (f) HRTEM image of this single CR NF of NF3-100. (g) Corresponding SAED pattern of this single CR NF of NF3-100.

indicated by blue triangles, appeared at values of $2 \theta$ of 9.30 , $11.90,17.41,18.32$, and $25.75^{\circ}$, respectively. Interestingly, two emergent peaks, indicated by red rhombuses, were observed at values of $2 \theta$ of 10.55 and $10.65^{\circ}$, corresponding to the (001) and (101) peaks, respectively, of $\beta$-CR. Furthermore, we used TEM and corresponding SAED patterns to investigate the molecular packing through substrate-assisted assembly of a single CR NF of NF3-100 after the normal thermal evaporation process. Fig. 4e displays a TEM image of CR-based NFs synthesized on the rGO-coated ITO substrate; no catalyst was evident at the tips after applying this fabrication process. HRTEM images (Fig. 4fg) of this CR-based NF exhibited fringes, suggesting that the CR molecules were stacked in short-range order at the edges of the NF, but entangled randomly within the NF. Thus, the SAED pattern evidences only diffuse rings, indicating predominantly amorphous structures of the CR-based NFs.

To optimize and validate the feasibility of PBA coating of our CR-based NF arrays, we conducted CA analyses of water droplets on NF1-100, NF2-100, and NF3-100 to estimate the wettability of all the carboxyl-functionalized surfaces. At room temperature, 2 $\mu \mathrm{L}$ water droplets were dispensed onto the surface of each sample, and the water CAs measured from at least five spots on every film were averaged. Fig. 5a-f reveal that the surfaces of NF1-100, NF2-100, and NF3-100 without PBA coatings were hydrophobic, with water CAs of $123.1 \pm 2.8,119.5 \pm 4.9$, and $114.3 \pm 5.3^{\circ}$, respectively. After the $1 \mathrm{~h}$ incubations with the aqueous PBA solution at $37{ }^{\circ} \mathrm{C}$, the surfaces of NF1-100, NF2100, and NF3-100 with the PBA coatings had become hydrophilic, with water CAs of $80.1 \pm 4.7,52.0 \pm 5.3$, and $49.2 \pm 6.1^{\circ}$, respectively. It is known that introducing surface roughness (e.g., increasing the aspect ratio and/or number density of NFs) can enhance the existing hydrophobicity of a material. We found, however, from our statistical analysis of the NF-related traits of NF1-100, NF2-100, and NF3-100 without PBA coatings, that the aspect ratio of the CR-based NFs displayed an inverse trend to the number density (Fig. S1c and $d \dagger$ ). Presumably this behavior is why the surfaces of NF1-100, NF2100, and NF3-100 without PBA coatings (Fig. 5a-f) were hydrophobic with similar water CAs of approximately $120^{\circ}$ each. The different degrees of decrease in the water CAs after PBA coating suggest different surface morphologies for the NF arrays, and offer a possible explanation for the different NF diameters and densities on the various electrodes. Therefore, we suspected that the nature of the PBA immobilized on the various NF electrodes would have an important effect on the capture yields of the CTCs. To quantify how much PBA had adhered to the CRbased NF arrays, we used survey XPS to determine the changes in the atomic percentages of carbon $(\mathrm{C})$ and oxygen $(\mathrm{O})$ atoms on the surface of NF3-100 before and after coating with PBA. Fig. $5 \mathrm{~g}$ presents typical XPS survey spectra of pristine NF3-100 and of NF3-100 with the PBA coating; these spectra reveal that 3.26 at\% of oxygen was present after the PBA coating (arising 

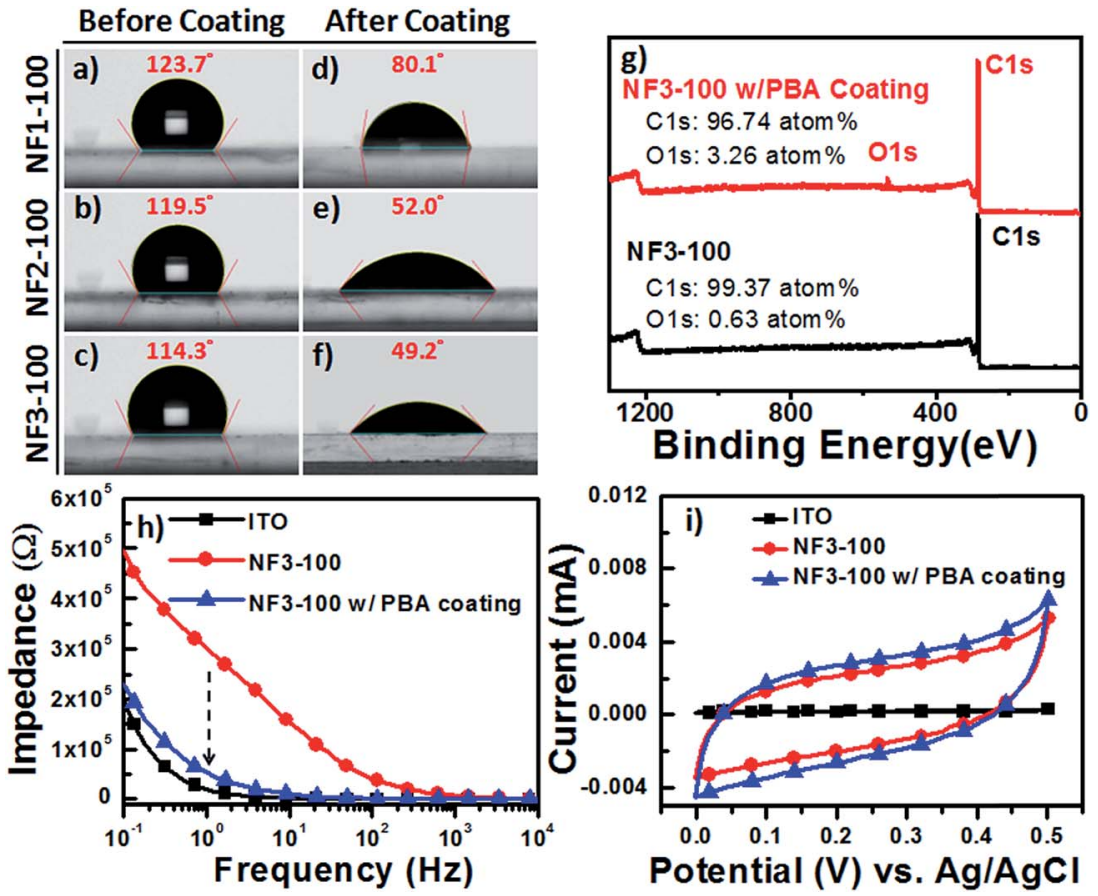

Fig. 5 (a-f) Wettability of CR films formed on various electrodes under the $500 \mathrm{~nm}$-thickness deposition conditions, before and after coating with PBA: $(a, d)$ CAs of NF1-100 before and after PBA coating, respectively; (b, e) CAs of NF2-100 before and after PBA coating, respectively; (c, f) CAs of NF3-100 before and after PBA coating, respectively. (g) XPS survey spectra of NF3-100 before and after PBA coating. (h, i) Electrical properties of ITO glass and NF3-100 before and after PBA coating in $1 \times$ PBS: (h) EIS spectra (frequency range, 1 to $10^{4} \mathrm{~Hz}$ ); (i) CV traces: potential swept from 0 to $0.8 \mathrm{~V}$ at a scan rate of $100 \mathrm{mV} \mathrm{s}^{-1}$. CCDs for ITO, NF3-100, and NF3-100 with PBA coating were 2.0, 21.8, and 27.1 $\mu \mathrm{C} \mathrm{cm}^{-2}$, respectively.

from the carboxyl-functionalized surface), whereas oxygen atoms were scarce $(0.63$ at $\%)$ for the pristine NF3-100. To explore the possibility of using these surfaces in bioelectronic applications under electrochemical operation, ${ }^{32,40-42}$ we recorded EIS and CV data for ITO, NF3-100, and NF3-100 with the PBA coating, employing a standard three-electrode system in $1 \times$ PBS (0.1 M, pH 7.2). First, we used EIS to measure the impedance of the devices in the frequency range from $10^{-1}$ to $10^{4} \mathrm{~Hz}$ (Fig. 5h). Although the impedance of NF3-100 at $1 \mathrm{~Hz}$ was approximately six times higher than that of the bare ITO electrode in $1 \times$ PBS $(0.1 \mathrm{M}, \mathrm{pH} 7.2)$, due to the former's inherent hydrophobicity, the $\pi-\pi$ stacking of the PBA coating on the NF3-100 surface would greatly enhance the ionic transport properties at the electrolyte-substrate interface, thereby decreasing the impedance close to the similar magnitude of ITO electrodes over the test frequency range. Furthermore, CV revealed a charge capacity density (CCD) for NF3-100 with the PBA coating $\left(27.1 \mu \mathrm{C} \mathrm{cm}^{-2}\right)$ that was higher than that of the ITO electrode $\left(2 \mu \mathrm{C} \mathrm{cm}^{-2}\right)$, suggesting greater capability for electrostatic surface charge accumulation; therefore, we suspected that NF3-100 with the PBA coating might behave as a functional capacitor, allowing the release of cells from biotinylated antiEpCAM-coated CR-based NF arrays through the following cyclic potential ES.

We used an inverted fluorescence microscope to obtain various views of fluorescence images of MCF7 cells captured on NF3-100. The photoluminescence (PL) of NF3-100 appeared in the range from 450 to $625 \mathrm{~nm}$ after UV excitation at $400 \mathrm{~nm}$, with a green PL color onset at $575 \mathrm{~nm}$ and a maximum at $502 \mathrm{~nm}$ (Fig. S2a †). ${ }^{5}$ Accordingly, the CR-based NF arrays (green) appeared as nanograss structures, allowing the cell nuclei to be stained with DAPI (blue) and the cell membranes to be stained with $\mathrm{DiD}$ (red) for investigations of the interactions between the cells and the CR-based NF electrodes (Fig. 6). The fluorescence image in Fig. 6e of the DAPI-stained cell nuclei on the CR-based $\mathrm{NF}$ arrays helped us to establish the nanostructures that induced enhanced endocytosis in the captured MCF7 cells, thereby providing direct evidence for enhanced CTC capture. More interestingly, the fluorescence intensity of the nanostructures after UV excitation was higher than that of the DAPIstained cell nuclei, presumably because of fluorescence resonance energy transfer (FRET) with the quenching capability of CR toward DAPI dyes. ${ }^{43,44}$

Although the fluorescence images of the MCF7 cells could be used to study the cell-substrate interactions, the overlapping fluorescence bands for the blue (DAPI) and green (CR) signals was an inconvenience when attempting to count the number of blue-stained nuclei on our CR-based NF arrays. Therefore, we investigated the optimal time required to achieve cell capture (Fig. 7a-f) through Papanicolaou staining with hematoxylin and eosin (H\&E), and further used light microscopy to count the captured cell densities on the CR-based NF arrays. For the EpCAM-positive MCF7 cells, the correlation between the incubation time and the number of captured cells on NF3-100 

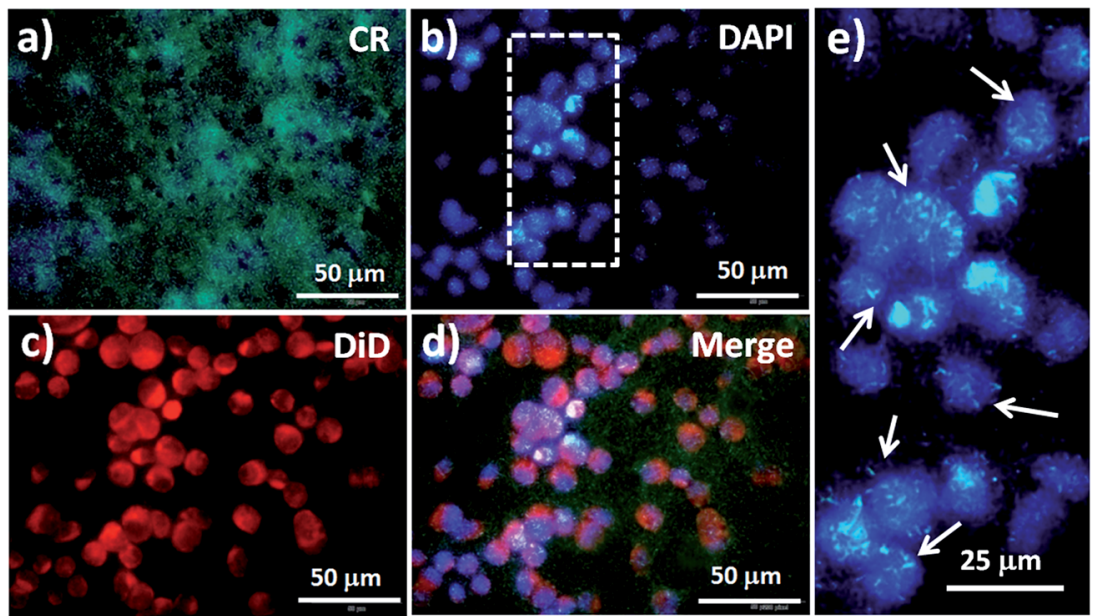

Fig. 6 Fluorescence images of fixed MCF7 cells captured on NF3-100 with DAPI and DiD staining. (a) CR-based NF array film (green). (b, c) MCF7 cells stained with (b) DAPI for cell nucleus (blue) and (c) DiD for cell membrane (red). (d) Merged image. (e) Magnified view of the fluorescence image of MCF7 cells stained with DAPI.

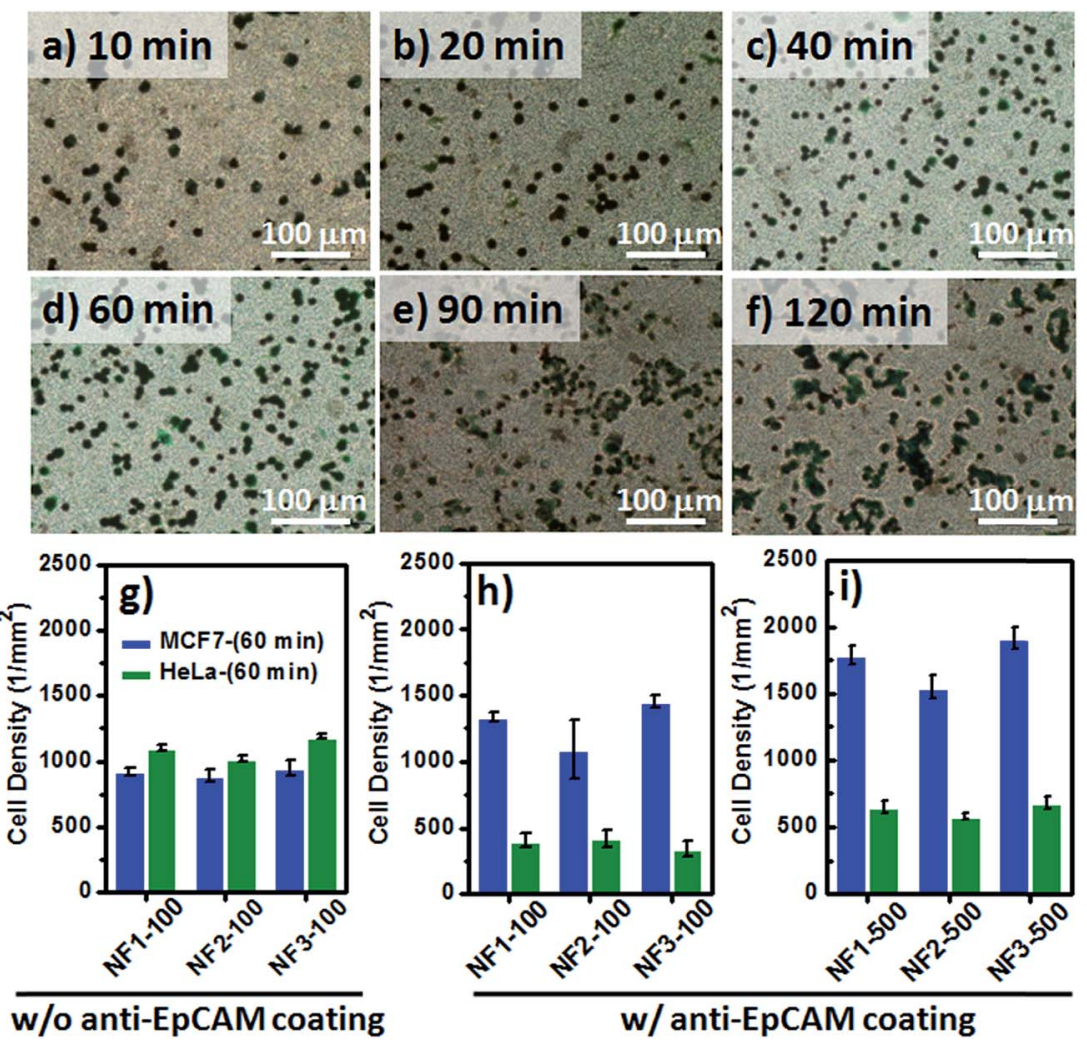

Fig. 7 (a-f) H\&E staining images of MCF7 cells captured on NF3-100 with increasing incubation time (from 10 to 120 min); scale bars: $100 \mu$ m. (g-i) Quantitative evaluations of capture yields of various CR-based NF array films on MCF7 [EpCAM-(+)] and HeLa cells [EpCAM-(-)]: (g) NF1100, NF2-100, and NF3-100 without anti-EpCAM conjugation; (h) NF1-100, NF2-100, and NF3-100 with anti-EpCAM conjugation; (i) NF1-500, NF2-500, and NF3-500 with anti-EpCAM conjugation.

suggested that the maximum cell-capture occurred after an incubation time of 60 min (Fig. S2b $\dagger$ ). The cell-capture specificity of NanoVelcro chips for CTC isolation is strongly related to the degree of coating of the antibodies on the nanostructures. To investigate the synergistic effect of nanostructures and antibodies on the specific cell-capture performance when using the anti-EpCAM-coated CR-based NF arrays, we chose an EpCAM-positive cell line (human breast cancer cell line, MCF7) and an EpCAM-negative cell line (cervical cancer cell line, HeLa) as target and control cell lines, respectively (Fig. 7g-i). The 
pristine CR-based NF arrays (NF1-100, NF2-100, NF3-100) without the anti-EpCAM coating exhibited higher nonspecific cell adhesion for the HeLa cells than for the MCF7 cells (Fig. 7g), possibly related to the higher intrinsic strength of the cellsubstrate adhesion of HeLa cells. The introduction of the SA/ anti-EpCAM coating led to a distinct decrease in the number of nonspecifically bound HaLa cells, thereby enhancing the cellcapture density from $920 \pm 27$ (NF1-100), $889 \pm 51$ (NF2-100), and $950 \pm 59$ (NF3-100) cells per $\mathrm{mm}^{2}$ to $1340 \pm 38$ (NF1-100), $1089 \pm 220$ (NF2-100), and $1459 \pm 46$ (NF3-100) cells per $\mathrm{mm}^{2}$, respectively. Based on the statistical analysis of the NF-related traits of NF1-500, NF2-500, and NF3-500 in Fig. S1, $\dagger$ we conclude that the number-density of CR-based NFs might have played a significant role in affecting the CTC capture efficiency.

As an alternative to fluorescence imaging, we used SEM to further understand why the capture efficiency of NF3-500 was better than that of NF1-500 and NF2-500. The SEM images in Fig. 8a-d reveal that a number of outer cell membranes were indented to fold closely around the top of the CR-based NFs and that MCF7 cells having a better spreading morphology, with extended pseudopodia of the cellular structures, grasped the surface of NF3-500. In comparison, fewer cells were folded close around the NF structures and the cell spreading morphologies were poorer when adhered on the surfaces of NF1-500 and NF2500. Furthermore, the strong cell adhesive forces between the target MCF7 cells and the NF structures arose because there were many NFs tilted in either direction, allowing specific cell interactions with the microvilli (Fig. 8d).

Although many cell-capture technologies have been developed for the efficient capture and isolation of rare CTCs from the blood of cancer patients, next-generation CTC chips should also have the capability of releasing the captured CTCs for downstream biological analysis..$^{25,27-29,33,38,45}$ For example, in a previous report we found that nanostructured 3D electrodes

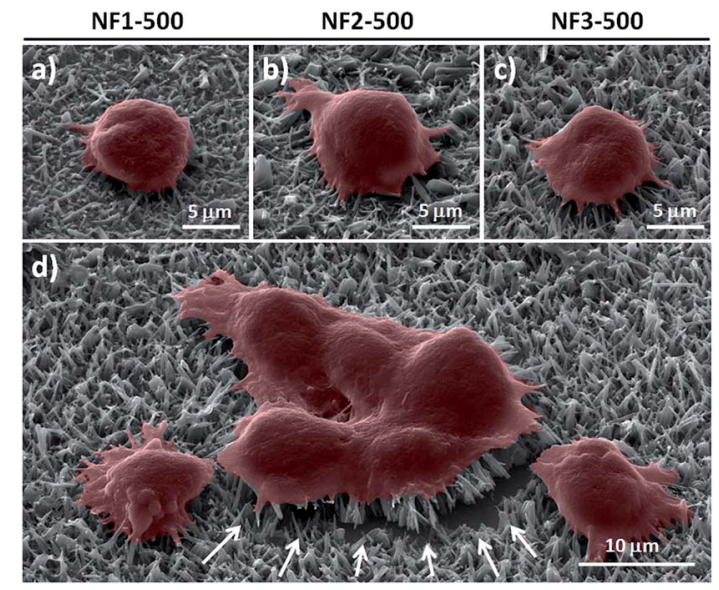

Fig. $8(\mathrm{a}-\mathrm{c})$ Representative SEM images of MCF7 cells captured on CR-based NF devices using various transparent conducting electrodes (ITO, GO-coated ITO, rGO-coated ITO) with anti-EpCAM conjugation: (a) NF1-500 device; (b) NF2-500 device; (c) NF1-500 device. (d) SEM micrograph of an MCF7 cluster captured on the NF1-500 device. Typical lamellipodia and filopodia were found with strong cellsubstrate interactions. functionalized with PLL-grafted polyethylene glycol (PLL- $g$ PEG)-biotin/SA/biotinylated-anti-EpCAM coatings can bind targeted cancer cells, but feature a passivated surface to avoid the background adsorption of nontargeted cells, while also having the ability to remove the captured CTCs under an electrochemical ES. ${ }^{32}$ More importantly, it is possible to apply this universal coating onto 3D-BEI electrodes with the goal of dynamically controlling cell-substrate interactions, allowing multiple rounds of capture and release, using different surface markers, thereby matching the requirements for a heterogeneous mixture of pooled CTCs. In this regard, we integrated PLL-g-PEG-biotin coatings onto our PBA-modified CR-based NF arrays; here, we demonstrate that the optimized NF3-100 device was applicable for CTC isolation and downstream characterization through dynamic control over the cell adhesive properties through cyclic potential ES on chips (Fig. 9a-d). In addition to MCF7 and HeLa cancer cell lines, we also tested the cellcapture efficiency of the NF3-100 device toward other EpCAMpositive (PC9) and EpCAM-negative (THP1) cell lines (Fig. 9c). Our results reveal that the synergistic effects of the (PLL- $g$-PEG)biotin/SA/biotinylated anti-EpCAM-modified NF1-100, NF2-100, and NF3-100 devices preserved the higher cell-capture efficiencies of targeted MCF7 and PC9 cancer cells relative to those in control experiments of planar rGO/ITO electrodes without CRbased NFs, while mitigating the nonspecific binding of nondemanded HeLa and THP1 cells. To investigate the voltage required to ensure sufficient cell release, we applied 20 cycles of a variety of $\mathrm{CV}$ sweeping conditions (voltages swept from -0.8 to $+0.5 \mathrm{~V}$; from 0 to $+0.5 \mathrm{~V}$; from 0 to $+0.8 \mathrm{~V}$; from 0 to $+1.0 \mathrm{~V}$ ) at a scan rate of $100 \mathrm{mV} \mathrm{s}^{-1}$ and measured the decreases in the cell densities on the NF3-100 devices (Fig. 9d). The cell capture density on the NF3-100 device decreased by $99.94 \%$ when the sweeping voltage was in the range from 0 to $+1.0 \mathrm{~V}$; this cellrelease performance was higher than that of the others, presumably because of the higher positive CCD level of the CRbased NF surfaces and/or more local changes in $\mathrm{pH}$ during a cyclic potential of ES. ${ }^{32,46}$ Furthermore, we used a trypan blue assay to evaluate the viability of the cells released from our CRbased 3D BEI devices; we observed a viability of greater than $90 \%$, potentially sustaining the primary culture through to subculturing. Furthermore, fluorescence images of MCF7 cells captured on the NF structures of NF3-100 through the static capturing mechanism revealed greater cell-capture efficiency than that of MCF7 cells on the planar structure of rGO/ITO electrodes (Fig. 9e). In addition to these evaluations of the static cell-capture performance on different 3D CR-based BEI devices, we further integrated the NF3-100 devices with an overlaid PDMS chaotic mixer to highlight that our device platform has potential applicability with physiological relevance to CTC isolation, when spiking various MCF7 cell numbers (100, 200 , and 500) into a $1 \mathrm{~mL}$ THP1 cell (a type of white blood cell) solution $\left(10^{6}\right.$ cells per $\mathrm{mL}$ ) (Fig. 9f and S3†). By integrating the basic design of a previously reported PDMS chaotic mixer with our CR-based NFs substrates, ${ }^{28}$ we found that the target cells were readily captured on NF3-100 at the optimized flow rate of $0.5 \mathrm{~mL} \mathrm{~h}^{-1}$ [isolating nearly $85 \%$ of the target MCF7 cells from non-target THP1 cell solution $\left(10^{6}\right.$ cells per $\left.\left.\mathrm{mL}\right)\right]$ (Fig. S3 $\dagger$ ). We 

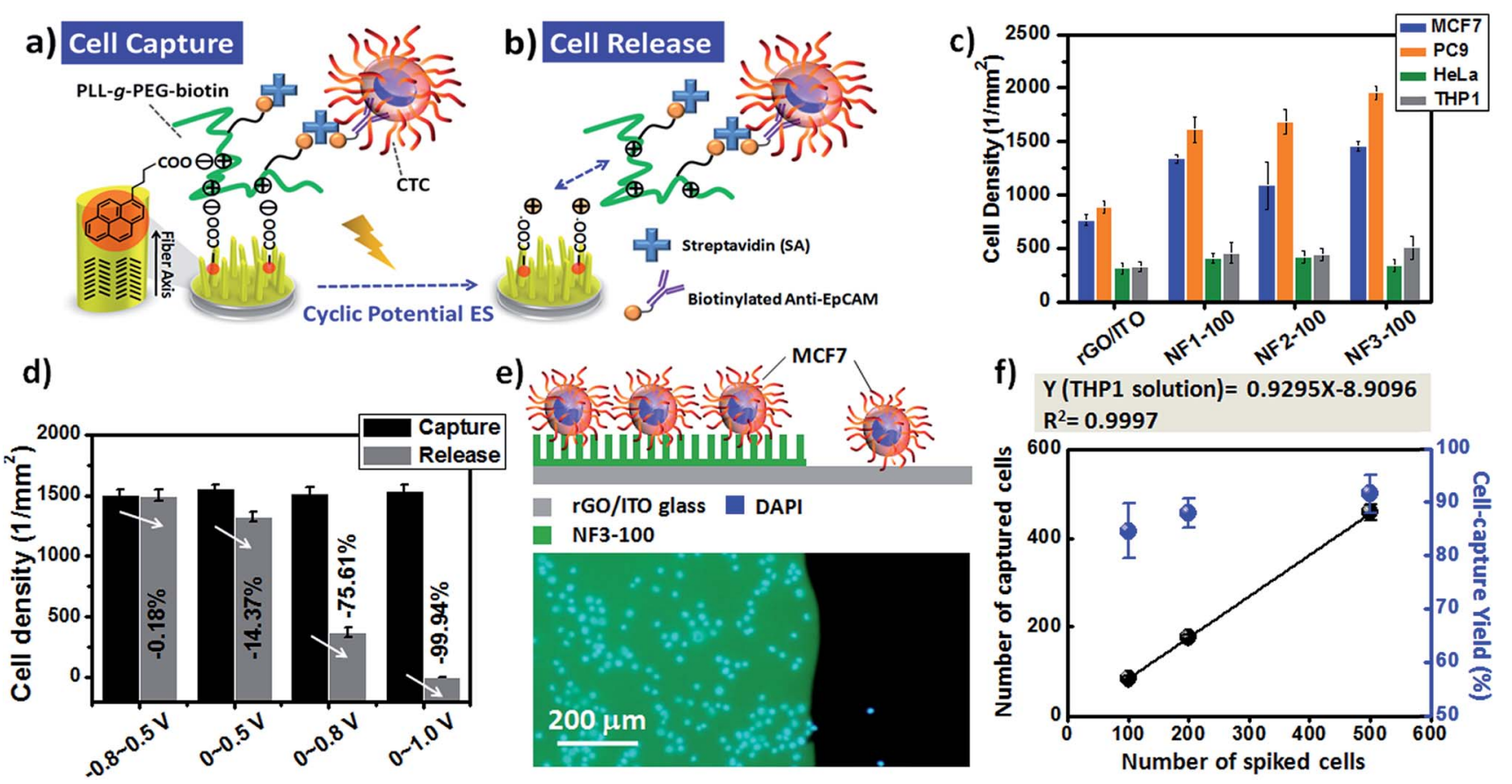

Fig. 9 (a, b) Schematic representation of PLL-g-PEG-biotin surface modifications for a 3D CR-based NF array device and its mechanism for the capture of CTCs and electrically triggered cell release on chips; (c) cell capture: cell-capture efficiencies from suspensions of MCF7 [EpCAM-(+)], PC9 [EpCAM-(+)], HeLa [EpCAM-(-)], and THP1 [EpCAM-(-)] cell lines on PLL-g-PEG-biotin/SA/biotinylated anti-EpCAM-coated BEl devices; (d) cell release of MCF7 by applying cyclic potential ES in 1× PBS buffer. (e) Fluorescence image of MCF7 cells captured on (left) the NF structures of NF3-100 and (right) the planar structure of rGO/ITO electrode. (f) Capture efficiencies of various contents of MCF7 cells in a white blood cell solution $\left(10^{6}\right.$ cells per $\mathrm{mL}$ ) after integration of the CR-based NFs substrate with an overlaid microfluidic PDMS chaotic mixer. Error bar represents variations among at least three repeating samples.

also used it to capture known numbers of MCF7 cells from a THP1 cell solution $\left(10^{6}\right.$ cells per $\left.\mathrm{mL}\right)$ at a series of densities from 100 to 500 cell per mL (Fig. 9f). Notably, the cell-capture yield at each different spiked cell density was greater than 84\%; thus, our NF3-100 device with an overlaid microfluidic PDMS chaotic mixer exhibited efficient performance for isolating rare MCF7 cells from $10^{6}$ cells per $\mathrm{mL}$ of a THP1 white blood cell solution.

\section{Conclusions}

We have employed an OSM semiconductor thin-film growth technology for the fabrication of 3D CR-based NFs on a variety of ITO electrodes, and further developed this BEI technology for integration into a bioelectronic device system that provided extremely sensitive CTC isolation and efficient cell recovery. After TE deposition, we formed CR-based NFs through template-assisted self-assembly, with a major portion of $\gamma$-CR structures and a minor portion of $\beta$-CR structures, as confirmed using GIXRD and SAED. Water CA measurements and XPS analyses confirmed the surface modifications of PBA coatings onto the NF surfaces for better use in bioconjugation. EIS and CV revealed that the $\pi-\pi$ stacked PBA coating on the CR-based NF arrays exhibited low impedance and high CCD properties, thereby facilitating the operation and stability of BEI devices during the cyclic potential of ES. Nanovelcro cell-affinity assays using the prepared 3D CR-based NFs films revealed extremely high capture efficiencies for CTCs, ascribed to the synergistic effects of the nanoscale topography and the immobilization of the biological CTC markers. Comparing the CR-based NF array devices fabricated on the ITO, GO-modified ITO, and rGOmodified ITO electrodes, the higher fiber density of the 3D CR-based NFs in the NF3-100 devices led to cell-capture efficiency of CTCs superior to that of corresponding NF1-100 and NF2-100 devices. In addition, the longer fibers of the 3D CRbased NFs in the NF3-500 devices improved the cell-capture efficiency of CTCs relative to that of the NF3-100 devices. The sharp decrease in the degree of nonspecific cell adhesion on the PBA-modified CR-based NF arrays, compared with that on pristine CR films without the PBA modification, suggested that the negative charge of PBA and/or the specific biotin-SA interaction most likely hindered the nonspecific cell adhesion. Furthermore, the negatively charged PBA-modified CR-based NF devices facilitated dynamic control over the adsorption/ desorption properties of a PLL-g-PEG-biotin coating while retaining the enhanced cell-capture performance toward CTCs; this system provided an electrically driven cell-release function through a simple and rapid ES process. The optimized electrically driven cell-release for our NF3-100 devices with PLL- $g$ PEG-biotin coatings occurred when applying 20 cycles of CV sweeping ES (voltage swept from 0 to $+1.0 \mathrm{~V}$ ) in $1 \times$ PBS buffer. The cell-capture yield at each different spiked cell density of MCF7 cells in a THP1 cell solution $\left(10^{6}\right.$ cells per $\left.\mathrm{mL}\right)$ was greater than $84 \%$ after integrating the NF3-100 with an overlaid 
microfluidic PDMS chaotic mixer. We hope that, through this proof-of-concept demonstration of an integrated 3D BEI device prepared through self-assembly of small-molecule semiconductors during a thermal evaporation process, our experimental results will bridge the gap between OSM devices and bioelectronics, thereby extending the range of device operating mechanisms and accelerating the development of nextgeneration bioelectronic medicines.

\section{Acknowledgements}

This study was supported by the Ministry of Science and Technology (MOST) of Taiwan (Grant No. MOST 105-2221-E131-039- and MOST 106-2622-E-131-003-CC2).

\section{References}

1 J. E. Anthony, A. Facchetti, M. Heeney, S. R. Marder and X. Zhan, Adv. Mater., 2010, 22, 3876-3892.

2 T. M. Figueira-Duarte and K. Mullen, Chem. Rev., 2011, 111, 7260-7314.

3 C. Wang, H. Dong, W. Hu, Y. Liu and D. Zhu, Chem. Rev., 2012, 112, 2208-2267.

4 H. Ma, H.-L. Yip, F. Huang and A. K. Y. Jen, Adv. Funct. Mater., 2010, 20, 1371-1388.

5 T. Sekitani and T. Someya, Adv. Mater., 2010, 22, 2228-2246. 6 X. Guo, M. Baumgarten and K. Müllen, Prog. Polym. Sci., 2013, 38, 1832-1908.

7 H. Liu, J. Xu, Y. Li and Y. Li, Acc. Chem. Res., 2010, 43, 14961508.

8 J. Frischeisen, D. Yokoyama, A. Endo, C. Adachi and W. Brütting, Org. Electron., 2011, 12, 809-817.

9 M. O'Neill and S. M. Kelly, Adv. Mater., 2011, 23, 566-584.

10 Y.-S. Hsiao, W. T. Whang, S. C. Suen, J.-Y. Shiu and C.-P. Chen, Nanotechnology, 2008, 19, 415603.

11 A. W. Hains, Z. Liang, M. A. Woodhouse and B. A. Gregg, Chem. Rev., 2010, 110, 6689-6735.

12 K.-J. Huang, Y.-S. Hsiao and W.-T. Whang, Org. Electron., 2011, 12, 686-693.

13 K.-J. Huang, Y.-S. Hsiao and W.-T. Whang, Org. Electron., 2011, 12, 1826-1834.

14 K.-J. Huang, Y.-S. Hsiao, J.-H. Huang, C.-W. Chu, P. Chen and W.-T. Whang, J. Mater. Chem., 2012, 22, 7837-7844.

15 S. Lai, M. Demelas, G. Casula, P. Cosseddu, M. Barbaro and A. Bonfiglio, Adv. Mater., 2013, 25, 103-107.

16 J. Reeder, M. Kaltenbrunner, T. Ware, D. Arreaga-Salas, A. Avendano-Bolivar, T. Yokota, Y. Inoue, M. Sekino, W. Voit, T. Sekitani and T. Someya, Adv. Mater., 2014, 26, 4967-4973.

17 S. Bonetti, A. Pistone, M. Brucale, S. Karges, L. Favaretto, M. Zambianchi, T. Posati, A. Sagnella, M. Caprini, S. Toffanin, R. Zamboni, N. Camaioni, M. Muccini, M. Melucci and V. Benfenati, Adv. Healthcare Mater., 2015, 4, 1190-1202.

18 M. Yu, A. Bardia, B. S. Wittner, S. L. Stott, M. E. Smas, D. T. Ting, S. J. Isakoff, J. C. Ciciliano, M. N. Wells, A. M. Shah, K. F. Concannon, M. C. Donaldson,
L. V. Sequist, E. Brachtel, D. Sgroi, J. Baselga, S. Ramaswamy, M. Toner, D. A. Haber and S. Maheswaran, Science, 2013, 339, 580-584.

19 C. Alix-Panabieres and K. Pantel, Clin. Chem., 2013, 59, 110118.

20 R. Harouaka, Z. Kang, S. Y. Zheng and L. Cao, Pharmacol. Ther., 2014, 141, 209-221.

21 L. Bai, Y. Du, J. Peng, Y. Liu, Y. Wang, Y. Yang and C. Wang, J. Mater. Chem. B, 2014, 2, 4080-4088.

22 S. Wang, H. Wang, J. Jiao, K. J. Chen, G. E. Owens, K. Kamei, J. Sun, D. J. Sherman, C. P. Behrenbruch, H. Wu and H.-R. Tseng, Angew. Chem., Int. Ed., 2009, 48, 8970-8973.

23 L. Chen, X. Liu, B. Su, J. Li, L. Jiang, D. Han and S. Wang, Adv. Mater., 2011, 23, 4376-4380.

24 S. Wang, K. Liu, J. Liu, Z. T. Yu, X. Xu, L. Zhao, T. Lee, E. K. Lee, J. Reiss, Y. K. Lee, L. W. Chung, J. Huang, M. Rettig, D. Seligson, K. N. Duraiswamy, C. K. Shen and H.-R. Tseng, Angew. Chem., Int. Ed., 2011, 50, 3084-3088.

25 S. Hou, H. Zhao, L. Zhao, Q. Shen, K. S. Wei, D. Y. Suh, A. Nakao, M. A. Garcia, M. Song, T. Lee, B. Xiong, S. C. Luo, H.-R. Tseng and H.-H. Yu, Adv. Mater., 2013, 25, 1547-1551.

26 H. Liu, X. Liu, J. Meng, P. Zhang, G. Yang, B. Su, K. Sun, L. Chen, D. Han, S. Wang and L. Jiang, Adv. Mater., 2013, 25, 922-927.

27 Q. Shen, L. Xu, L. Zhao, D. Wu, Y. Fan, Y. Zhou, W. H. Ouyang, X. Xu, Z. Zhang, M. Song, T. Lee, M. A. Garcia, B. Xiong, S. Hou, H.-R. Tseng and X. Fang, Adv. Mater., 2013, 25, 2368-2373.

28 M. Lin, J. F. Chen, Y. T. Lu, Y. Zhang, J. Song, S. Hou, Z. Ke and H.-R. Tseng, Acc. Chem. Res., 2014, 47, 2941-2950.

29 J. F. Chen, Y. Zhu, Y. T. Lu, E. Hodara, S. Hou, V. G. Agopian, J. S. Tomlinson, E. M. Posadas and H. R. Tseng, Theranostics, 2016, 6, 1425-1439.

30 J. Sekine, S.-C. Luo, S. Wang, B. Zhu, H.-R. Tseng and H.-H. Yu, Adv. Mater., 2011, 23, 4788-4792.

31 Y.-S. Hsiao, S.-C. Luo, S. Hou, B. Zhu, J. Sekine, C.-W. Kuo, D.-Y. Chueh, H.-H. Yu, H.-R. Tseng and P. Chen, Small, 2014, 10, 3012-3017.

32 Y.-S. Hsiao, B.-C. Ho, H.-X. Yan, C.-W. Kuo, D.-Y. Chueh, H.-H. Yu and P. Chen, J. Mater. Chem. B, 2015, 3, 5103-5110.

33 S. Hou, L. Zhao, Q. Shen, J. Yu, C. Ng, X. Kong, D. Wu, M. Song, X. Shi, X. Xu, W. H. OuYang, R. He, X. Z. Zhao, T. Lee, F. C. Brunicardi, M. A. Garcia, A. Ribas, R. S. Lo and H. R. Tseng, Angew. Chem., Int. Ed., 2013, 52, 3379-3383.

34 N. Zhang, Y. Deng, Q. Tai, B. Cheng, L. Zhao, Q. Shen, R. He, L. Hong, W. Liu, S. Guo, K. Liu, H.-R. Tseng, B. Xiong and X. Z. Zhao, Adv. Mater., 2012, 24, 2756-2760.

35 H.-C. Tseng, A.-W. Lee, P.-L. Wei, Y.-J. Chang and J.-K. Chen, J. Mater. Chem. B, 2016, 4, 6565-6580.

36 Y. Li, Q. Lu, H. Liu, J. Wang, P. Zhang, H. Liang, L. Jiang and S. Wang, Adv. Mater., 2015, 27, 6848-6854.

37 F. Zhang, Y. Jiang, X. Liu, J. Meng, P. Zhang, H. Liu, G. Yang, G. Li, L. Jiang, L. J. Wan, J. S. Hu and S. Wang, Nano Lett., 2016, 16, 766-772.

38 L. Wang, H. Liu, F. Zhang, G. Li and S. Wang, Small, 2016, 12, 4697-4701. 
39 J. Potticary, L. R. Terry, C. Bell, A. N. Papanikolopoulos, P. C. Christianen, H. Engelkamp, A. M. Collins, C. Fontanesi, G. Kociok-Kohn, S. Crampin, E. Da Como and S. R. Hall, Nat. Commun., 2016, 7, 11555.

40 Y.-S. Hsiao, C.-C. Lin, H.-J. Hsieh, S.-M. Tsai, C.-W. Kuo, C.-W. Chu and P. Chen, Lab Chip, 2011, 11, 3674-3680.

41 C.-H. Lu, Y.-S. Hsiao, C.-W. Kuo and P. Chen, Biochim. Biophys. Acta, 2013, 1830, 4321-4328.

42 Y.-S. Hsiao, C.-W. Kuo and P. Chen, Adv. Funct. Mater., 2013, 23, 4649-4656.
43 K. Takazawa, J. Inoue and K. Mitsuishi, Nanoscale, 2014, 6, 4174-4181.

44 J. Choi, W. Lee, C. Sakong, S. B. Yuk, J. S. Park and J. P. Kim, Dyes Pigm., 2012, 94, 34-39.

45 S. Hou, H. Zhao, L. Zhao, Q. Shen, K. S. Wei, D. Y. Suh, A. Nakao, M. A. Garcia, M. Song, T. Lee, B. Xiong, S. C. Luo, H. R. Tseng and H. H. Yu, Adv. Mater., 2012, 25, 1547-1551.

46 O. Guillaume-Gentil, Y. Akiyama, M. Schuler, C. Tang, M. Textor, M. Yamato, T. Okano and J. Vörös, Adv. Mater., 2008, 20, 560-565. 